\title{
Stroke in the Young Adults: 6-Year Case Series of Community Hospital Stroke Unit
}

\author{
Sabrina Anticoli*, Maria Cristina Bravi, Francesca Romana Pezzella \\ Stroke Unit Emergency Department, San Camillo Hospital, Rome, Italy \\ Email: santicoli@scamilloforlanini.rm.it
}

Received 12 July 2015; accepted 26 September 2015; published 30 September 2015

Copyright (C) 2015 by authors and Scientific Research Publishing Inc.

This work is licensed under the Creative Commons Attribution International License (CC BY). http://creativecommons.org/licenses/by/4.0/

(c) (i) Open Access

\section{Abstract}

Stroke etiology in young adults and older patient differs considerably, as well as epidemiology and clinical features vary according to geographical criteria. To improve clinical management and optimize diagnostic work-up of young adults with acute cerebrovascular events, we analyzed retrospectively data of 6-year stroke unit case series. In this hospital case series study, we enrolled 145 patients with acute cerebrovascular events aged 16 to 49 , consecutively admitted to a Community Hospital Hub Stroke Unit. We studied risk factors for stroke, the distribution of acute cerebrovascular events, stroke subtype, length of stay and clinical outcome: $70 \%$ of patients were admitted for acute ischemic event ( 45 female-F, 57 male-M), 10.5\% intracranial hemorrhages (5F, $10 \mathrm{M}), 2.7 \%$ subarachnoid hemorrhage $(2 \mathrm{~F}, 2 \mathrm{M}), 2 \%$ venous sinus thrombosis $(3 \mathrm{~F}), 14.5$ for acute ischemic attack (12F, 9M). Among ischemic stroke patients, the etiology was as follows: atherothrombosis $29.4 \%$, cardioembolism $19.6 \%$, arterial dissection $13.7 \%$, other determined causes $8.8 \%$, lacunar stroke $5.8 \%$, and undetermined causes $22.54 \%$. $15 \%$ of ischemic young patients were treated with r-TPA. The majority of patients returned home at discharge, whereas $\mathbf{3 0 \%}$ needed intensive rehabilitation programme to regain independence in the activity of daily living. Dedicated health care programme targeting prevention and optimizing treatment of acute cerebrovascular events in young adults are desirable to improve prognosis among this socioeconomically active age group.

\section{Keywords}

Stroke, Young, Cerebrovascular Disease, Etiology

\section{Introduction}

Acute cerebrovascular events may have a dramatic impact on young adults, the occurrence of stroke in subjects

\footnotetext{
${ }^{*}$ Corresponding author.
}

How to cite this paper: Anticoli, S., Bravi, M.C. and Pezzella, F.R. (2015) Stroke in the Young Adults: 6-Year Case Series of Community Hospital Stroke Unit. Open Journal of Emergency Medicine, 3, 23-27. 
under the age of 45 is approximately 5.0\% in western countries [1] and is higher in non-industrialized countries and in black populations [2]; etiology, risk factors and outcome of young stroke populations vary markedly between countries [3] and differ considerably to the older population group, whereas clinical features seem to have no specificity in young people. In Italy, there are 196,000 new strokes each year, 6200 of these subjects are under the age of 45 years old and 6200 subjects are aged between 45 and 55 years old [4] [5]. To improve clinical management and optimize diagnostic work-up of this socioeconomically active age group with acute cerebrovascular events we analyzed retrospectively data of 6-year stroke unit activity.

\section{Materials and Methods}

The Stroke Unit at S. Camillo-Forlanini Hospital is a Hub Stroke Center, it is a 8-bed residential facility (2 beds in a sub-intensive care environment, 6 beds in a regular ward) managed by a multidisciplinary team with 24 hours access to laboratory facility, neuroimaging, neurosurgery and cardiology services. Population served is 2.6 million living in both urban and rural area. Clinical and laboratory assessment included 1) in all patients: collection of historical data according to a standard form comprising questions about cardiovascular risk factors and trauma, neurologic and cardiovascular evaluation, standard biochemical blood and urine tests, standard electrocardiography (ECG), and computed tomography (CT scan) carried out within 12 after the onset of symptoms, and MRI (DWI and angio-MRI) within 48 hours; 2) in hemorrhagic patients: selective vessel angiography; 3) in ischemic patients: two dimensional (2-D) echocardiography, echo color Doppler ultrasonography, 24-hour Holter ECG monitoring, and immunologic and coagulation tests including omocysteine plasmatic concentration, antithrombin III and lupus inhibitor, MTHFR assessment.

\section{Results}

In this hospital case series study, we enrolled 145 patients with acute cerebrovascular events aged 16 to 49, consecutively admitted to the Stroke Unit between the 30th June 2006 and 31 May 2011. Seventy percent of patients were admitted for acute ischemic event (42 female-F, 57 male-M), 10.5\% intracranial hemorrhages (5F, 10M) $2.7 \%$ subarachnoid hemorrhage (2F, 2M), $2 \%$ venous sinus thrombosis (6F) (Figure 1), $14.5 \%$ for acute ischemic attack $(12 \mathrm{~F}, 9 \mathrm{M})$, mortality was $2.05 \%(\mathrm{~N}=3)$. Demographic characteristics and etiology are summarized in Table 1.

Concerning risk factors a diagnosis of hypertension was based on at least two blood pressure recordings during admission with systolic pressure of $>160 \mathrm{~mm} \mathrm{Hg}$ or diastolic pressure of $>90 \mathrm{~mm} \mathrm{Hg}$, history of hypertension, or previous/current antihypertensive treatment, 52 patients fulfilled this criteria (19 woman 33 men), smoking habits was present in 39 subjects ( $47.58 \% 37$ woman, 32 men), family history of cerebrovascular disease was present in 39 (26.89\% 18 woman, 21 men), history of diabetes in 14 (9.65\%, 7 men, 7 women), thrombophilic conditions were encountered in 21 patients, including hyperhomocysteinemia $(\mathrm{N}=12,3$ men, 9 women) MTHFR homozygosis [3], vasculitis ( $\mathrm{N}=8,4$ men, 4 women) and endocarditis $(\mathrm{N}=2)$, arterial dissection was diagnosed in 14 subjects with ischemic stroke (6 men, 8 women).

Among ischemic stroke patient the etiology was as follows: atherothrombosis $29.4 \%$, cardioembolism $19.6 \%$, arterial dissection $13.7 \%$, other determined causes $8.8 \%$, lacunars stroke $5.8 \%$, and undetermined causes $22.54 \%$; stroke severity at admission was 4.9 NIHSS (5.80 man, 4.12 woman) and at discharge 2.03 (2.48 man and 1.58 woman). Patent Foramen Ovale was diagnosed in 14 patients, 5 underwent closing procedure according to local professional expert consensus. Thrombolytic therapy with r-TPA was performed in 16 patients (8 men, 8 women). A 27-year-old woman presenting with seizures was diagnosed venous sinus thrombosis complicated with Arnold-Chiari malformation.

A 26-year-old Indian immigrant woman was diagnosed Moya-Moya disease (Figure 2). Most patients returned home at discharge and within 1 month were back at their productive life, 28 patients needed to carry on a residential intensive rehabilitation programme for 60 days after stroke unit discharge.

\section{Conclusion}

The main differences between ischemic strokes occurring in young adults and those occurring later in life are the breakdown of causes, with a prominence of "unknown" and "other determined" causes, and an overall favorable outcome. Depending on how exhaustive the diagnostic work-up [5]-[7] is, up to $50 \%$ of patients have no clearly 

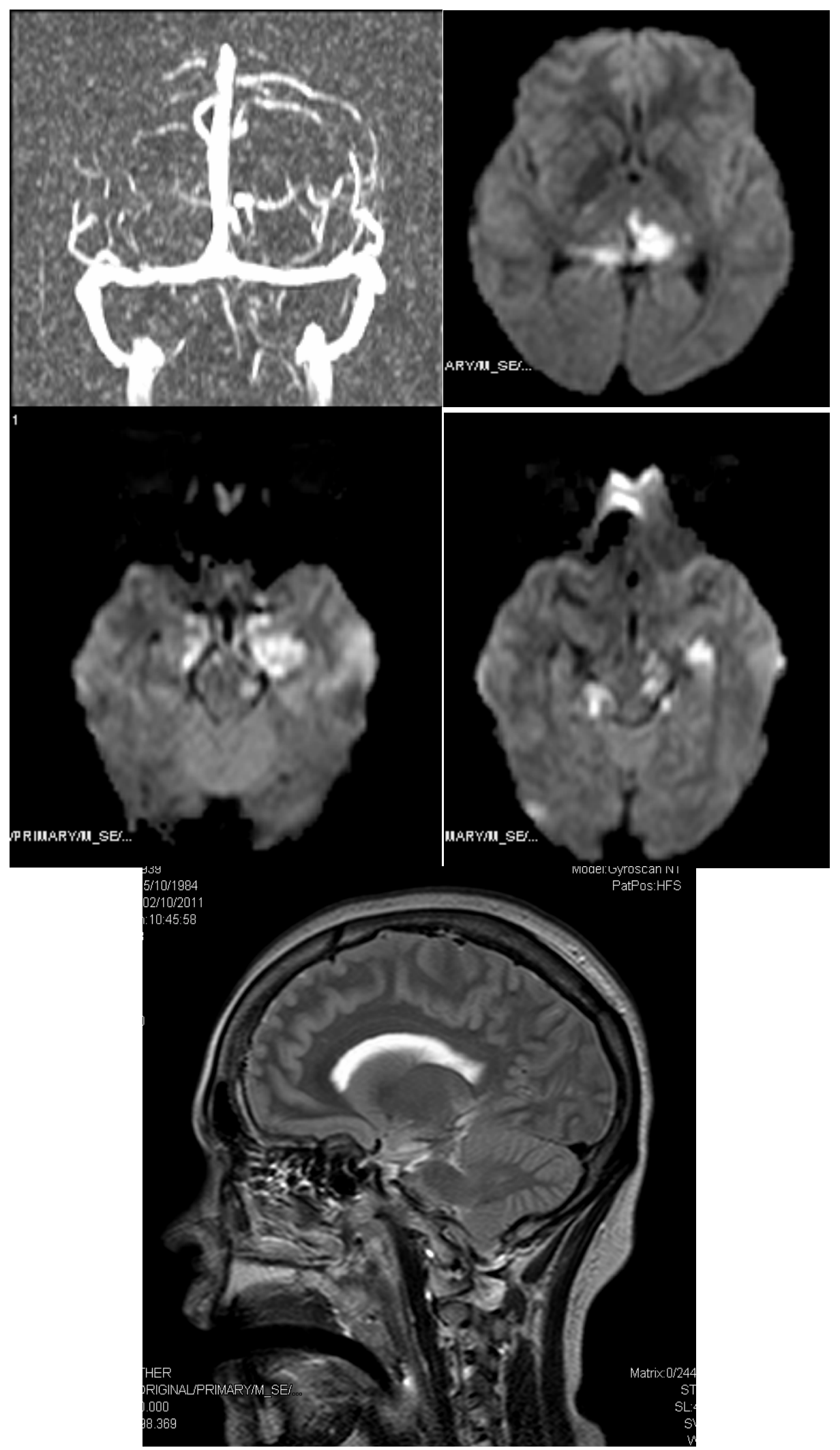

Figure 1. A 27-year-old woman presenting with seizures was diagnosed venous sinus thrombosis complicated with Arnold-Chiari malformation. 


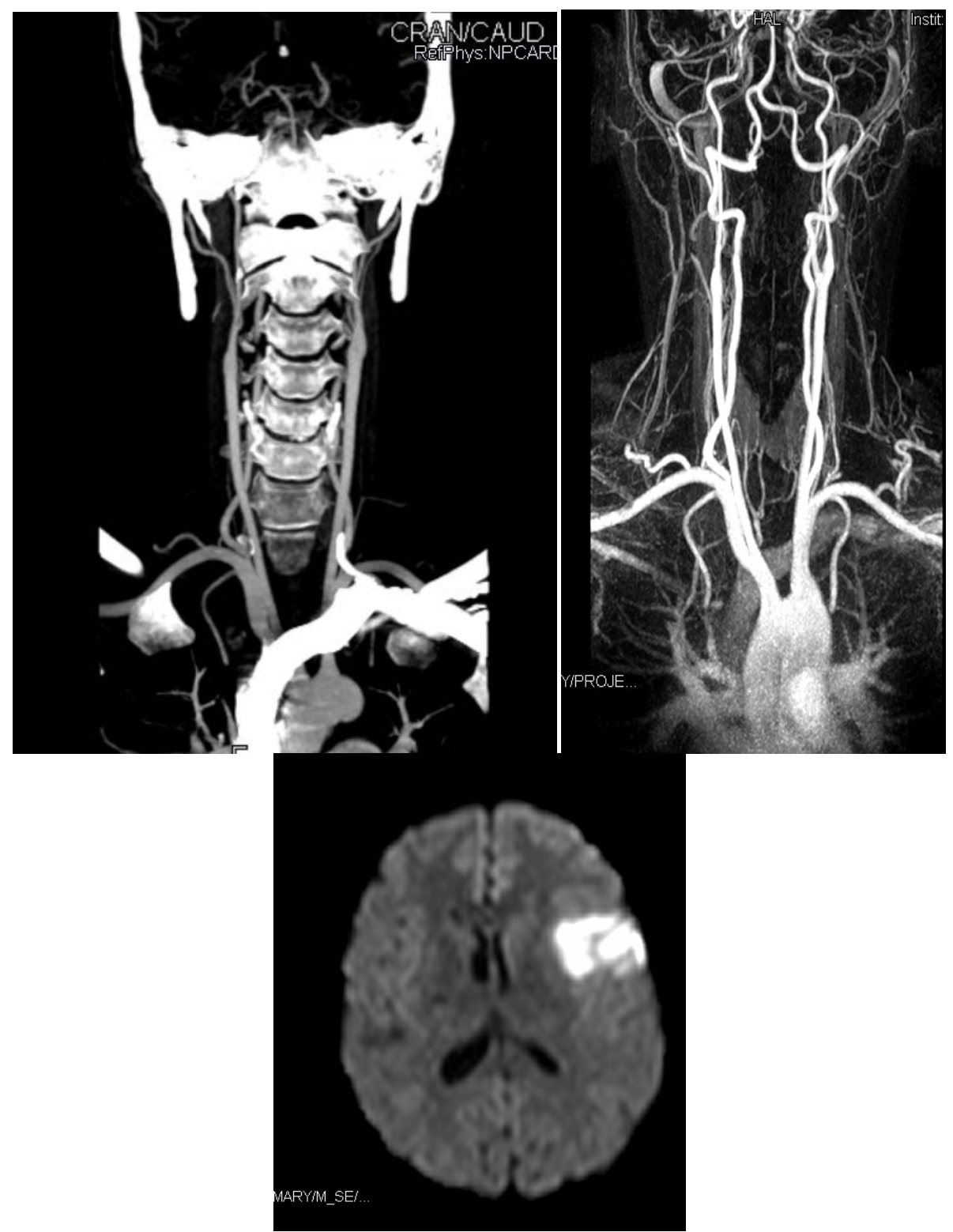

Figure 2. A 26-year-old Indian immigrant woman presenting with right arm hypostenia, dysphasia and headache was diagnosed Moya-Moya.

Table 1. Demographic characteristics and type of acute cerebrovascular events causing stroke unit admission.

\begin{tabular}{cccc}
\hline & Female 46.2\% (67) & Male 53.8\% (78) & Total (145) \\
\hline Age & 39.65 (DS 7.4) & 42.14 (DS) & 40.8 \\
Age range & $16-49$ & $14-49$ & $44-49$ \\
Median age & 42 & 44 & \\
Cerebrovascular event: & & & \\
- Ischemic stroke & $42(28.9 \%)$ & $57(39.3 \%)$ & $99(68.27 \%)$ \\
- Intracharanial hemorrhage & $5(3.44 \%)$ & $10(6.88 \%)$ & $15(10.34 \%)$ \\
- Venous sinus thrombosis & $6(4.13 \%)$ & nihil & $6(4.13 \%)$ \\
- Subarachnoid hemorrhage & $2(1.37 \%)$ & $2(1.37 \%)$ & $4(2.75 \%)$ \\
- Subdural hematoma & $1(0.68)$ & nihil & $1(0.68)$
\end{tabular}


identified cause. In our case series we could identify stroke etiology in almost 80\% patients; atherothrombosis was the most common cause that may be due to the age limit (49) and depend on the definition of "young". Three upper thresholds can be found in the literature, at age of 30, 45 and 55. The most frequently used upper age limit is 45 years old. We chose 49 as a compromise between literature data and Italian ageing life expectancy. As our national social and demographic structure of the population is in constant evolution and change, especially in his younger component, we consider the presumed cause, the natural history of the disease and the long life expectancy to improve prevention, management and outcome of cerebrovascular disorders in young adult therapeutic options.

\section{References}

[1] Nencini, P., Inzitari, D., Baruffi, M.C., Fratiglioni, L., Gagliardi, R., Benvenuti, L., et al. (1988) Incidence of Stroke in Young Adults in Florence, Italy. Stroke, 19, 977-981. http://dx.doi.org/10.1161/01.STR.19.8.977

[2] Bonita, R. (1992) Epidemiology of Stroke. Lancet, 339, 342-344. http://dx.doi.org/10.1016/0140-6736(92)91658-U

[3] Hoffmann, M. (2000) Stroke in the Young in South Africa-An Analysis of 320 Patients. South African medical journal, 90, 1226-1237.

[4] Putaala, J., Metso, A.J., Metso, T.M., Konkola, N., Kraemer, Y., Haapaniemi, E., et al. (2009) Analysis of 1008 Consecutive Patients Aged 15 to 49 with First-Ever Ischemic Stroke. The Helsinki Young Stroke Registry. Stroke, 40, 1195-1203. http://dx.doi.org/10.1161/STROKEAHA.108.529883

[5] Marini, C., Totaro, R., De Santis, F., Ciancarelli, I., Baldassarre, M. and Carolei, A. (2001) Stroke in Young Adults in the Community-Based L’Aquila Registry: Incidence and Prognosis. Stroke, 32, 52-56. http://dx.doi.org/10.1161/01.STR.32.1.52

[6] Cotter, P.E., Agarwal, S. and Martin, P.J. (2011) Etiologic Investigation of Ischemic Stroke in Young Adults. Neurology, 77, 1932-1933. http://dx.doi.org/10.1212/WNL.0b013e318239c0e8

[7] Larrue, V., Berhoune, N., Massabuau, P., Calviere, L., Raposo, N., Viguier, A. and Nasr, N. (2011) Etiologic Investigation of Ischemic Stroke in Young Adults. Neurology, 76, 1983-1988.

http://dx.doi.org/10.1212/WNL.0b013e31821e5517 